\title{
Biocatalytic protein membranes fabricated by electrospinning
}

\author{
Gözde Kabay ${ }^{\mathrm{a}}$, Gizem Kaleli ${ }^{\mathrm{a}}$, Zahida Sultanova ${ }^{\mathrm{a}}$, Tolga Tarkan Ölmez ${ }^{\text {c,d }}$, \\ Urartu Özgür Şafak Șeker ${ }^{c, d, *}$, Mehmet Mutlu ${ }^{\mathrm{b}, *}$
}

a Plasma Aided Biomedical Research Group (pabmed), Biomedical Engineering Division, Graduate School of Science and Technology, TOBB University of Economics and Technology,

Ankara 06560, Turkey

b Plasma Aided Biomedical Research Group (pabmed), Department of Biomedical Engineering, TOBB University of Economics and Technology, Ankara 06560, Turkey

c Institute of Materials Science and Nanotechnology, Bilkent University, Ankara 06800, Turkey

d UNAM-National Nanotechnology Research Center, Bilkent University, Ankara 06800, Turkey

\section{A R T I C L E I N F O}

\section{Article history:}

Received 12 October 2015

Received in revised form 4 March 2016

Accepted 21 March 2016

Available online 25 March 2016

\section{Keywords:}

Electrospinning

Bovine serum albumin

Glucose oxidase

Biocatalytic membrane

Amperometric detection

\begin{abstract}
A B S T R A C T
In this study, a protein-based catalytic membrane was produced by electrospinning. Membrane activity was characterised in terms of response current for various glucose concentrations. We focused on the preparation of a scaffold by converting a globular protein to other structural forms using catastrophic solvents. A scaffolding protein, bovine serum albumin, and an enzyme, glucose oxidase (GOD), were selected as a model natural carrier matrix and a biologically active agent, respectively. Beta-mercaptoethanol ( $\beta-\mathrm{ME}$ ) was used to convert the globular protein to an amyloid-like form. A structural stabilising agent, 2,2,2-triflouroethanol (TFE), was used to maintain the final $\alpha$-helical structure of the amyloid-like protein. The TFE:PBS (phosphate-buffered saline) ratio and various electrospinning parameters were analysed to minimise activity loss. Using this approach, we applied electrospinning to an active enzyme to obtain biocatalytic nanofibrous membranes. After optimising the protein electrospinning process, the activities of the protein nanofibrous membranes were monitored. GOD remained active in the new membrane structure. The highest enzyme activity was observed for the membranes prepared with a 1.5:1 (v:v) TFE:PBS solvent ratio. In that particular case, the immobilized enzyme created a current of $0.7 \mu \mathrm{A}$ and the apparent activity was $2547 \pm 132 \mathrm{U} / \mathrm{m}^{2}$.
\end{abstract}

(C) 2016 Published by Elsevier B.V.

\section{Introduction}

Electrospinning is a popular technique to produce nanofibrous structures using polymeric substances for a variety of applications [1-5]. The power of electrospinning mainly depends on the applicability of the technique to a number of different polymers with minor optimisation steps. Using the appropriate optimisation conditions, one can adjust the thickness, morphology, and length of a desired polymeric nanofibre [6]. Although electrospinning has been successfully applied to many synthetic polymeric materials, few studies have examined its application to natural polymers. One of the challenges in using natural polymers for electrospinning is their closed and densely packed structure. Combining proteins with polymers is one approach to overcome this limitation $[7,8]$. Additionally, some studies have recently examined direct electrospinning of proteins to form biological nanofibres [9]. Globular proteins, such as albumin [9-12], haemoglobin [5], and myoglobin [13], have been electrospun.

\footnotetext{
* Corresponding authors at: Söğütözü Caddesi No: 43, Söğütözü, Ankara 06560, Turkey. E-mail addresses: urartu@bilkent.edu.tr (U.Ö.S. Seker), m.mutlu@etu.edu.tr (M. Mutlu).
}

Our inspiration for protein electrospinning arose from the natural biological fibres secreted by diverse organisms. Biological protein fibres are generally secreted by specialised instruments, as in the case of the secretion of silk by Bombyx mori $[14,15]$. Silk is one of the oldest known protein fibres with functional properties. It has previously been reported that spider silk contains amyloid-like fibres when it is assembled in vitro [16]. Although biological fibres have many applications, the production of these natural fibres is not cost effective or efficient [17, 18]. In this context, the utilisation of electrospinning to produce protein-based natural fibres is promising. Using this approach, different proteins with various functionalities can be electrospun for biotechnology applications. One of the best methods for fabricating a biofunctional scaffold is to load a bioactive agent to the scaffold. The performance of the bioactive agent is strongly dependent on supporting structures at the nanoscale. For example, nanofibres minimise diffusion limitations [9]. However, owing to their structural arrangement, the electrospinning of proteins requires an intensive optimisation strategy. As mentioned in the work of Dror and coworkers for the electrospinning of bovine serum albumin (BSA), disulphide bonds should be broken to obtain an electrospinnable solution using a catastrophic solvent. This process causes the conversion of a protein into an amyloid-like form. Among various alcohols, beta-mercaptoethanol ( $\beta-\mathrm{ME})$ is mainly used 
to open the tertiary structure of proteins and $\alpha$-helical structures are stabilised by 2,2,2-triflouroethanol (TFE) [10].

In this article, a BSA-derived amyloid-like structure was used as a natural polymer for the electrospinning process to enhance the coating and supporting properties during the entrapment of a bioactive agent. In this scenario, the glucose oxidase (GOD) enzyme was chosen as a model bioactive agent. The negative effects of catastrophic solvents on enzymatic activity were studied. The ratio of the solvent to stabilising agent was carefully adjusted, as were the electrospinning parameters to minimise activity loss. The preliminary results for the performance of electrospun biocatalytic membranes are reported based on apparent enzyme activity.

\section{Experimental}

\subsection{Materials}

Glucose oxidase (EC 1.1.3.4.) from Aspergillus niger (specific activity: $306 \mathrm{U} / \mathrm{mg})$, TFE, $\beta-\mathrm{ME}, \mathrm{D}-(+)$ glucose monohydrate, and Congo red were purchased from Sigma Chemical Co. (St. Louis, MO, USA). All other reagents $\left(\mathrm{NaCl}, \mathrm{Na}_{2} \mathrm{HPO}_{4}\right.$, and $\left.\mathrm{NaH}_{2} \mathrm{PO}_{4}\right)$ used as buffering agents and BSA were supplied by Acros Organics (Morris Plains, NJ, USA). Double-distilled water was used throughout the experiments.

\subsection{Preparation of solutions and electrospinning}

The negative effect of catastrophic solvents on enzymatic activity was studied. BSA was dissolved in a mixture of TFE and phosphatebuffered saline (PBS) at a concentration of $12 \%(w: v)$ at room temperature. The tertiary structure of the protein was decomposed with 10 equiv. bond $\beta-\mathrm{ME}$ and stabilised by the addition of TFE at the following ratios: $1.5: 1.0,3.0: 1.0,4.5: 1.0$, and 9.0:1.0. The BSA-containing solvent was stirred continuously at $25{ }^{\circ} \mathrm{C}$ for $4 \mathrm{~h}$. After obtaining a clear solution of protein, the powdered enzyme corresponding to $200 \mathrm{U} / \mathrm{mL}$ final activity was added, stirred for $5 \mathrm{~min}$, and the final solution was transferred to an injector to begin the electrospinning process immediately. Accordingly, the interaction period for the enzyme, GOD, and catastrophic solvents was limited to diminish activity prior to the electrospinning process. The preparation protocol for the solution is summarised in Fig. 1.

For the electrospinning setup, a direct current voltage supplier ( $\mathrm{MCH}$ 303D2; Gamma High Voltage Research Inc., Ormond Beach, FL, USA) and a syringe pump (NE-1000; New Era Pump Systems Inc., Farmingdale, NY, USA) were used. The mixed solution was loaded into a 5-mL syringe with a vertically fixed metal needle (inner diameter, $0.80 \mathrm{~mm}$ ). In the vertical setup, the collector was placed on the floor and the syringe pump was located above the collector. The flow rates
(Q) were maintained between 0.20 and $0.60 \mathrm{~mL} / \mathrm{h}$ (Fig. 1). Fibres were collected on glass slides and aluminium foil. The applied voltage and the distance between the tip and the collector varied between 9 and $20 \mathrm{kV}$ and $10-20 \mathrm{~cm}$, respectively. All experiments were performed at room temperature (about $25^{\circ} \mathrm{C}$ ). The samples were then stored for $24 \mathrm{~h}$ in a vacuum desiccator.

\subsection{Characterisation}

Fiber morphologies were investigated by optical microscopy (Nikon Eclipse LV100, Nikon Instruments Inc., Melville, NY, USA) and scanning electron microscopy (SEM, FEI-Quanta 200; Hillsboro, OR, USA). The chemical surfaces of membranes were characterised by FTIR-ATR (Fourier transform infrared spectroscopy attenuated total reflectance) (Perkin Elmer, Waltham, MA, USA). After production, electrospun membranes were stained with Congo red using the methods by Puchtler et al. [19] in order to verify the formation of an amyloid-like structure [19].

\subsection{Measurement of enzyme activity}

The reaction sequence to monitor glucose utilisation of flavin adenine dinucleotide (FAD) is given as follows:

$\beta$-D-Glucose + GOD $(F A D) \rightarrow \beta$-D-Gluconolactone + GOD $\left(\mathrm{FADH}_{2}\right)$

$\mathrm{GOD}\left(\mathrm{FADH}_{2}\right)+\mathrm{O}_{2} \rightarrow \mathrm{GOD}(\mathrm{FAD})+\mathrm{H}_{2} \mathrm{O}_{2}$

$\mathrm{H}_{2} \mathrm{O}_{2} \rightarrow \mathrm{O}_{2}+2 \mathrm{H}^{+}+2 \mathrm{e}^{-}$

Apparent enzyme activity was measured by amperometric detection. Amperometric measurements were performed using the DropSens $\mu$ Stat 200 (Llanera, Spain). The DropSens electrode was polarised at $650 \mathrm{mV}$ to decompose hydrogen peroxide $\left(\mathrm{H}_{2} \mathrm{O}_{2}\right)$, which is formed during the reaction of glucose with oxygen in the presence of $\operatorname{GOD}(1,2)$. The electrons that result from the decomposition of hydrogen peroxide are proportional to the glucose concentration (3). They were tracked amperometrically and the response current (I) was recorded in units of $\mu \mathrm{A}$. The details of the amperometric measurements of enzymatic activity were described previously [20].

In the experimental setup, the electrospun membranes were placed in a 50-mL PBS solution and stirred for 10 min until equilibrium was reached. A stock glucose solution (200 mM) was added to the PBS solution to achieve a final concentration of $0.05-50 \mathrm{mM}$ glucose, and the solution was stirred continuously. Enzyme activities corresponding to different substrate concentrations were investigated based on response currents. This procedure was repeated several times until deviations from linearity were observed for all membranes. The optimum solvent

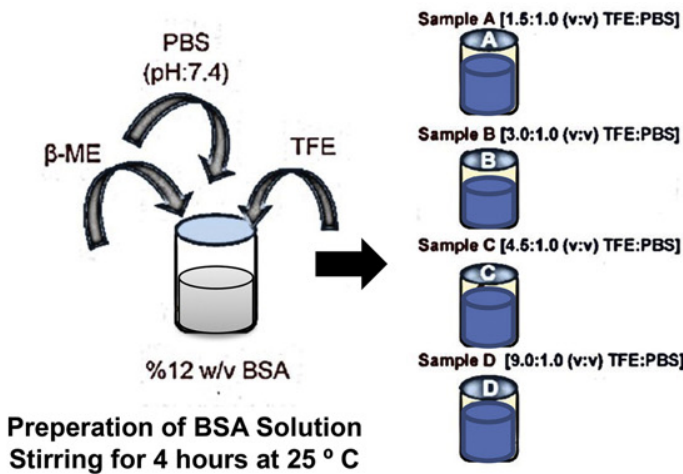

Amyloid-like BSA Solution Samples
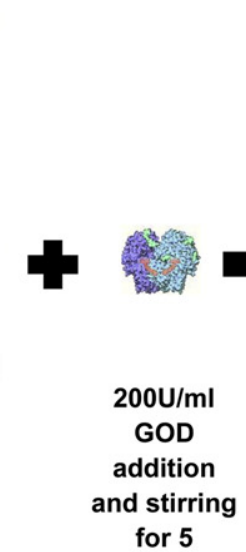

for 5
Sample A [1.5:1.0 (v:v) TFE:PBS] A 2

Sample B [3.0:1.0 (v:v) TFE:PBS] B (2) Sample C [4.5:1.0 (v:v) TFE:PBS] 5 (2)

Sample D [9.0:1.0 (v:v) TFE:PBS]

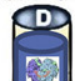
20)

Electrospinning Process

Fig. 1. Schematic representation of solution preparation and electrospinning setup. 
ratio was determined by the response current corresponding to highest apparent enzymatic activity.

Additionally, the effect of GOD content in electrospun membranes was investigated. Specifically, $200 \mathrm{U} / \mathrm{mL}, 100 \mathrm{U} / \mathrm{mL}$, and $50 \mathrm{U} / \mathrm{mL}$ GOD were added to the solution. The membrane with the highest activity (Sample A) was electrospun for different time intervals (1-60 min) in order to observe the effects of accumulation period on the total activity of the membrane. Resulting current values with respect to glucose concentration for "Sample A" were converted to apparent enzymatic activity using a calibration curve. Furthermore, amperometric measurements were repeated after $24 \mathrm{~h}$ for membranes kept in PBS to examine the degradation of enzyme activity.

\section{Results and discussion}

3.1. Preparation and characterisation of protein-based biocatalytic membranes

Protein electrospinning requires an optimisation strategy. A basic problem with the utilisation of proteins for electrospinning is their structural stability and closed loop structures compared to synthetic polymers. In this study, we performed a tedious optimisation procedure to determine the correct conditions for protein electrospinning. A common alpha helix structural stabiliser, TFE, causes damage to the structure and function of proteins [21]. To determine the effect of TFE concentration on fibre morphology and enzyme activity, four solutions were prepared. In a preliminary analysis, enzymatic activity in solutions with different TFE:PBS ratios was detected and the relative enzymatic activities of the solutions were as follows: Sample A > Sample B > Sample C > Sample D.

Electrospinning parameters were optimised for the solution that had the lowest TFE:PBS ratio (i.e., Sample A), but the highest enzyme activity. First, the effect of applied voltage was examined. We assumed that protein-based membranes are more susceptible to higher voltages than synthetic polymers. Previous studies have examined the effect of higher voltages, but these results were not applicable to our optimisation study, which examined large-scale variation in voltage values [22-25]. In our study, electrospinning was carried out using 9-20 kV to evaluate the effect of voltage. High voltages $(>12 \mathrm{kV})$ caused ruptures because the fibres were thinner, and lower voltages $(<12 \mathrm{kV})$ resulted in thicker fibres. The threshold voltage value for the spinning process was $9 \mathrm{kV}$ to obtain a considerable Taylor cone structure. SEM images of the fibres produced using these parameters are shown in Fig. 2A1 and Fig. 2A2. The nanofibres that were electrospun at $9 \mathrm{kV}$ had an average diameter of $612 \pm 64 \mathrm{~nm}$, and those that were electrospun at $12 \mathrm{kV}$ had an average diameter of $474 \pm 23 \mathrm{~nm}$. Keeping the voltage at $9 \mathrm{kV}$, despite the large fibre diameter, uniform fibres were observed. As a result, $9 \mathrm{kV}$ was chosen as the working voltage. Secondly, the effect of flow rate on fibre morphology was studied. Electrospinning was performed for flow rates of $0.20-0.60 \mathrm{~mL} / \mathrm{h}$. As the flow rate increased, the solvent became less prone to evaporation and the diameters of the resultant fibres increased. When the flow rate was greater than $0.50 \mathrm{~mL} / \mathrm{h}$, more than one jet (unstable Taylor cone) was observed. The fibres that were electrospun with a flow rate of $0.50 \mathrm{~mL} / \mathrm{h}$ had larger fibre diameters $(1096 \pm 124 \mathrm{~nm})$; however, those that were electrospun with a flow rate of $0.35 \mathrm{~mL} / \mathrm{h}$ had smaller fibre diameters $(632 \pm 23 \mathrm{~nm})$ and were more uniform. When the flow rate was less than $0.35 \mathrm{~mL} / \mathrm{h}$, a stable Taylor cone could not form. Consequently, $0.35 \mathrm{~mL} / \mathrm{h}$ was chosen as the working flow rate. Only the SEM images of fibres produced with flow rates of 0.35 and $0.50 \mathrm{~mL} / \mathrm{h}$ are shown in Fig. 2B1 and Fig. $2 \mathrm{~B} 2$.

Finally, the effect of the tip-to-collector distance was examined. When the distance was less than $10 \mathrm{~cm}$, the solvent did not evaporate and a fibrous network could not form. When the distance was greater than $20 \mathrm{~cm}$, the jet did not reach the collector. The effects of distances between 10 and $20 \mathrm{~cm}$ were evaluated. SEM images of fibres produced with distances of 8 and $12 \mathrm{~cm}$ to the collector are shown in Fig. $2 \mathrm{C} 1$ and Fig. 2C2, respectively. The membrane that was electrospun with a distance of $8 \mathrm{~cm}$ had an average diameter of $742 \pm 89 \mathrm{~nm}$, and the membrane that was electrospun with a $12-\mathrm{cm}$ distance had an average diameter of $323 \pm 18 \mathrm{~nm}$. The fibres shown in Fig. 2C1 are nonuniform and thick owing to the lack of solvent evaporation, which results from the small distance $(8 \mathrm{~cm})$. In contrast, the membranes shown in Fig. 2C2 are more uniform and thinner because the distance was increased.

Accordingly, the working parameters were optimised at $12 \mathrm{kV}$, $10 \mathrm{~cm}$, and $0.35 \mathrm{~mL} / \mathrm{h}$ for the solution with the lowest TFE concentration (Sample A). The other solutions (Samples B, C, and D) were further electrospun under these optimised conditions. The SEM images of all

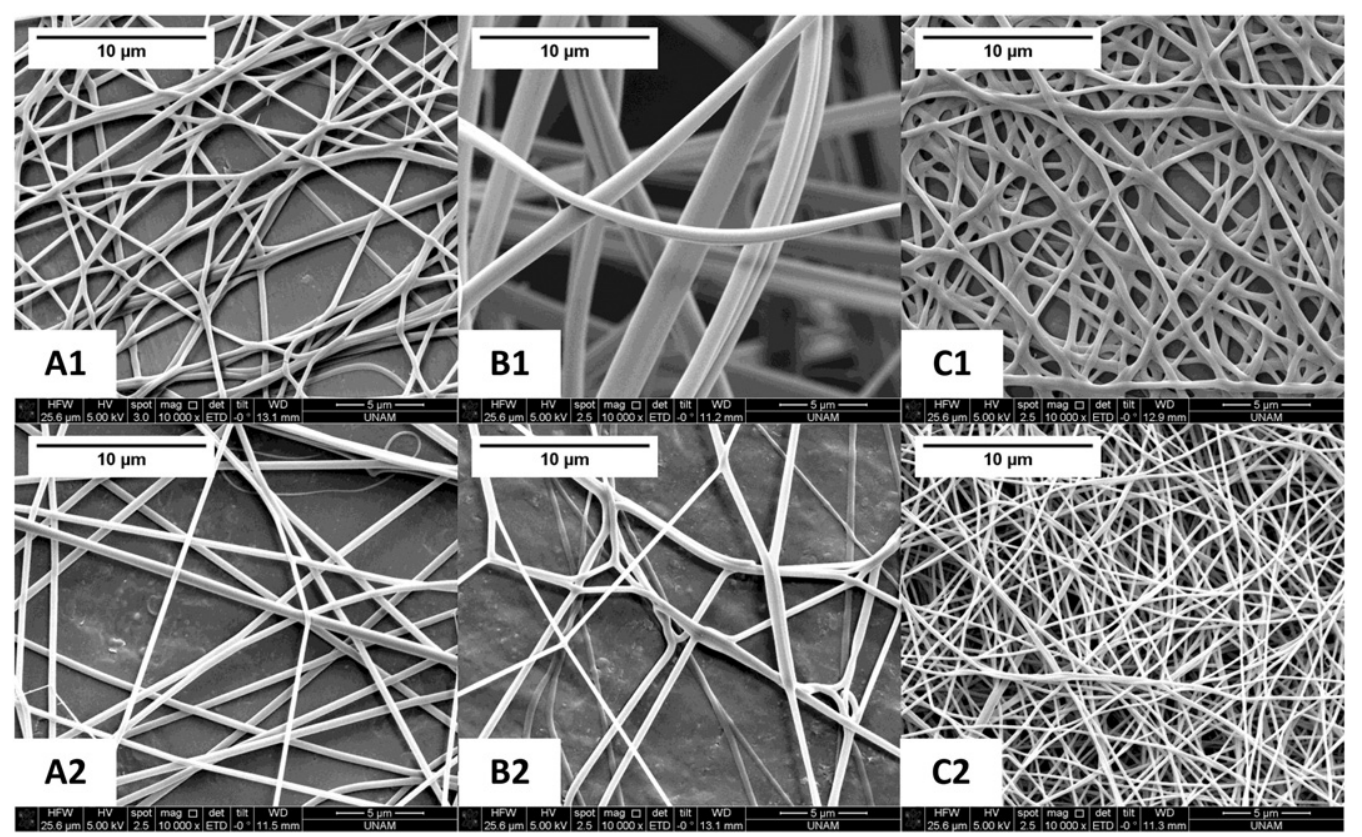

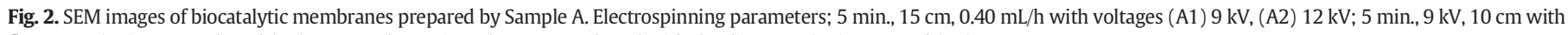
flow rates (B1) $0.50 \mathrm{~mL} / \mathrm{h}$ and (B2) $0.35 \mathrm{~mL} / \mathrm{h} ; 5 \mathrm{~min} ., 9 \mathrm{kV}, 0.35 \mathrm{~mL} / \mathrm{h}$ and with the distances (C1) $8 \mathrm{~cm}$ and (C2) $12 \mathrm{~cm}$. 


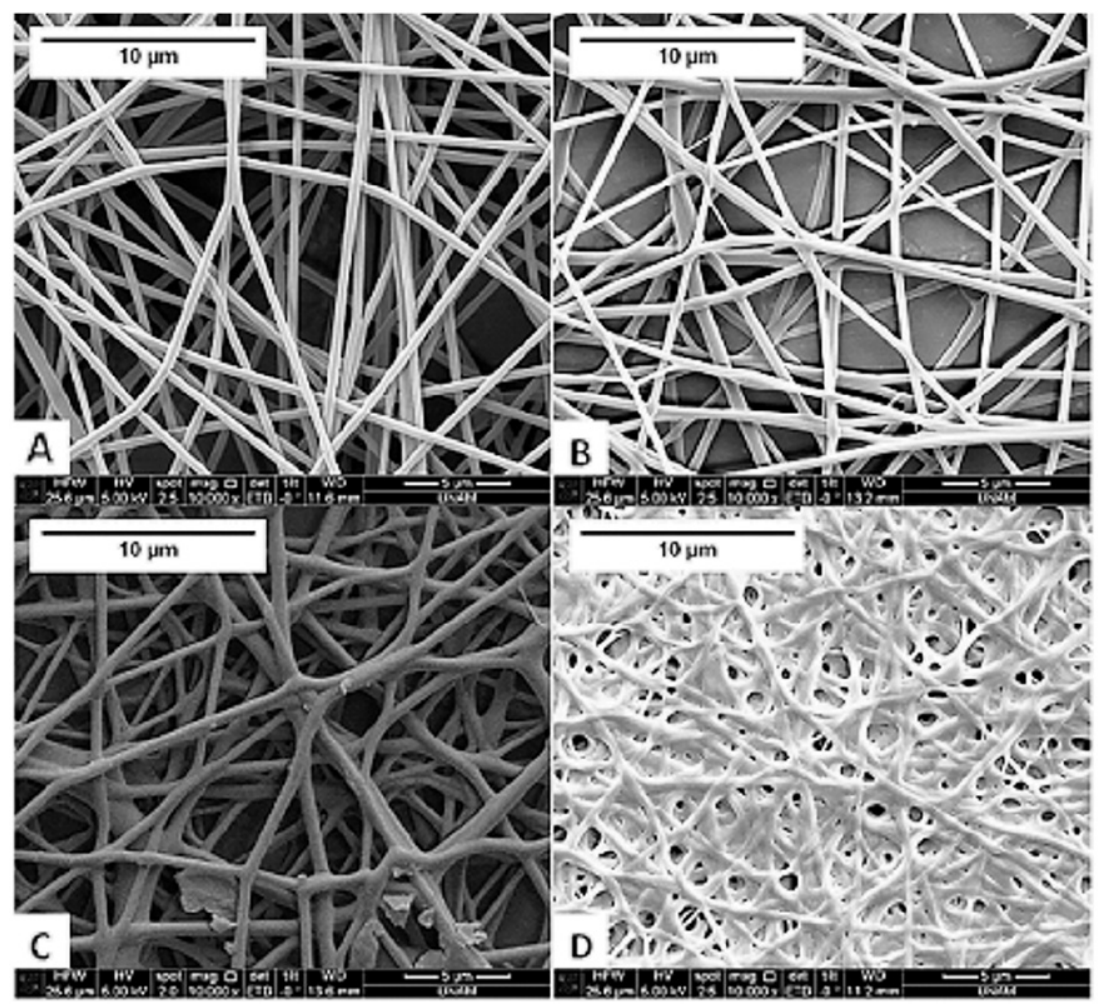

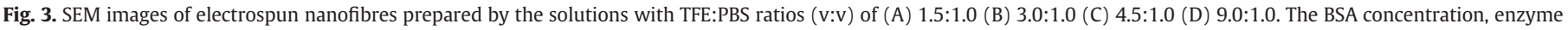

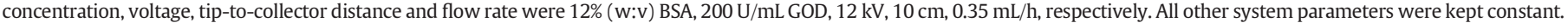

samples are shown in Fig. 3A-D. The nanofibres of Sample A showed uniform sizes with the smallest diameters ( $227 \pm 19 \mathrm{~nm})$. However nanofibres became less uniform as the TFE concentration increased (Samples B and C). The nanofibres of Sample B were uniform, but had thicker structures (552 $\pm 45 \mathrm{~nm}$ ) compared to the fibres produced using Sample A. A drastic deformation of fibre structure was observed for membranes prepared with Sample C. Finally, the membrane prepared with Sample D, with the highest TFE concentration, had a gellike structure because the solvent was not fully evaporated.

In order to demonstrate the amyloid-like formation of BSA in the electrospinning process, fibres stained with Congo red dye were observed under an optical microscope. As is clearly shown in Fig. 4, electrospun nanofibres sustained amyloid-like characteristics compared with nanofibres produced with the polycaprolactone polymer as a negative control. The amyloid-specific dye Congo red showed differences in amyloid membrane colour, while the polycaprolactone membrane did not show any difference after staining. Optical images of all protein fibres prepared using different parameters supported the amyloid-like form of the proteins (BSA and GOD) in the solutions [16].
Based on FTIR-ATR measurements, the amyloid-like structure of nanofibres was investigated. A broad peak between 1600 and $1700 \mathrm{~cm}^{-1}$ indicated the presence of an amide I band. In the case of GOD, the amide I band was the characteristic peak. The amide I band showed that the protein secondary structure included random coil and $\alpha$-helical conformations. As shown in Fig. 5, there was an obvious shift in the amide I band from $1646 \mathrm{~cm}^{-1}$ to $1660 \mathrm{~cm}^{-1}$ (from GOD to BSA-GOD). This may indicate the formation of a $\beta$-turn/antiparallel $\beta$ sheet conformation in the structure, i.e. the formation of an amyloidlike structure. There was also peak shift in the amide I band between BSA and BSA-GOD. These results showed that some GOD was converted to the amyloid-like form in the presence of catastrophic solvents [26].

\subsection{Enzyme activity studies}

\subsubsection{Effect of TFE concentration on enzyme activity}

The highest apparent enzyme activity was recorded for the fibres produced with the solution containing the lowest TFE concentration (Sample A). For Sample B and Sample C, the lower limit of enzyme

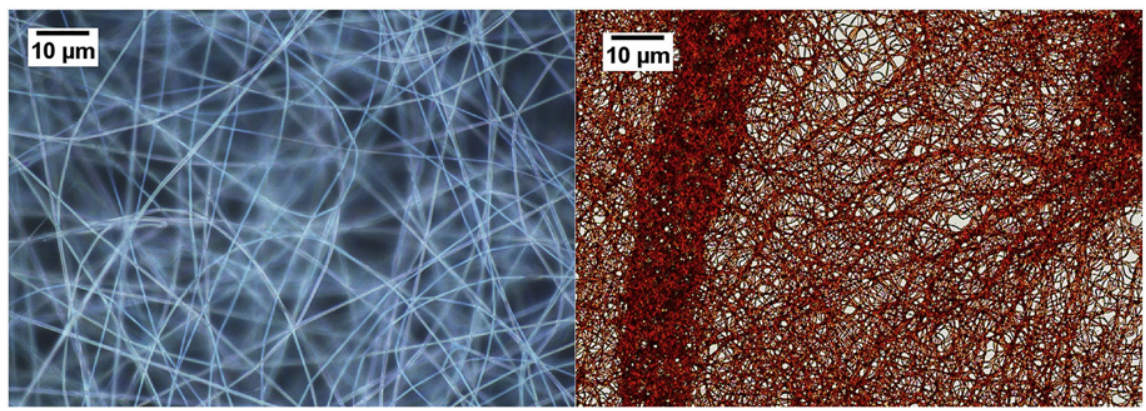

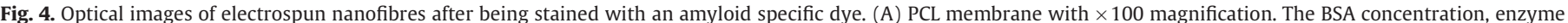

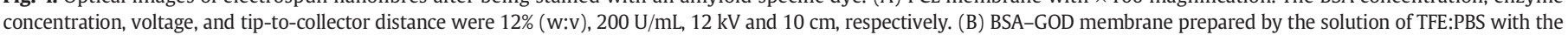
ratio of 1.5:1.0 (v:v). 


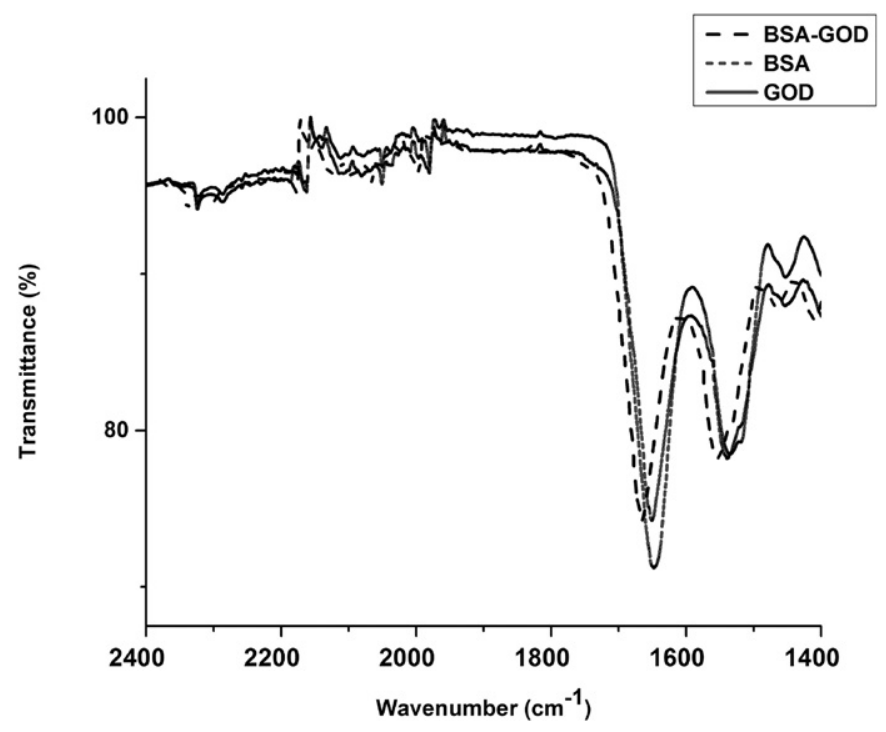

Fig. 5. FTIR-ATR Spectra of BSA-GOD nanofibres, BSA fibres and GOD.

activity detection was $0.1 \mathrm{mM}$ glucose; however, linearity was attained for $1.5 \mathrm{mM}$ and $2 \mathrm{mM}$ glucose, respectively. These conditions resulted in a limited detection interval. The lowest activity was recorded for the fibres produced with the solution containing the highest TFE concentration (Sample D), as expected. For Sample A, the linear range of glucose detection was $35 \mathrm{mM}$ glucose; however, the lower limit of detection for glucose was $2 \mathrm{mM}$.

For the membranes prepared using Sample D, the enzyme activity was so low that no response was observed for glucose concentrations above $5 \mathrm{mM}$; however, the limit of detection for Sample D was as low as $0.05 \mathrm{mM}$ glucose. The membranes prepared by Sample D can be used for the detection of low blood glucose levels owing to the low detection limit. However, the membranes prepared with Sample A can be used for normal and diabetic glucose detection, for which a larger detection interval is necessary.

\subsubsection{Effect of enzyme concentration}

The effect of enzyme concentration on enzyme activity was detected for the membranes prepared using Sample A, which had the highest activity in the previous analysis. The concentration of GOD did not affect the response current, substantially. These results can be explained by a diffusion-controlled mechanism of the glucose-GOD reaction in the electrospun nanofibre as well as the maximum enzymatic response upon severe destruction by TFE $[27,28]$. The effect of different GOD concentrations on enzyme activity is illustrated in Fig. 7.

The maximum currents were $0.72 \mu \mathrm{A}$ for the membrane with $200 \mathrm{U} / \mathrm{mL}$ enzymatic activity, $0.65 \mu \mathrm{A}$ for the membrane with $100 \mathrm{U} / \mathrm{mL}$ enzymatic activity, and as low as $0.30 \mu \mathrm{A}$ for the membrane with $50 \mathrm{U} / \mathrm{mL}$ enzymatic activity. It is speculated that as the amount of enzyme decreases, the current also decreases due to the reduction in total enzymatic activity. Another explanation for the decrease in current could be the limited diffusion of the substrate.

Such enzymatic reactions have been examined extensively in our research for more than 20 years. For example, the reaction of glucose with GOD in various conditions was intensively examined in our biosensor studies. In a preliminary analysis, the diffusion of GOD in a biological matrix, porcine mucus, was examined [29]. In another study, we reported the diffusion-limited reaction kinetics of GOD and glucose for sandwich-type enzyme electrode applications [30]. Further studies were carried out using cross-linked matrices [31]. The diffusion of glucose over the enzyme layers formed in different conditions affects the reaction kinetics as well as the performance of the enzyme electrode [32-33].

\subsubsection{Effect of accumulation time}

The effect of accumulation time was assessed using membranes prepared with Sample A and the results are shown in Fig. 8. It is quite clear that a longer period of fibre formation on the surface was associated with higher enzyme deposition on the surface. Accordingly, it is expected that as the accumulation time increases, the response or enzymatic activity will be higher. However, all response curves for membranes against glucose concentration showed a similar behaviour (Fig. 6). The membrane with the highest enzymatic activity was the one with an accumulation time of $1 \mathrm{~min}$. The membrane with $60 \mathrm{~min}$ of accumulation time, which had the greatest enzyme content, showed slightly less activity than the 1-minute sample. The samples with accumulation times of 10,20, and 40 min showed less activity than the 60-minute and 1-minute samples. These responses can only be explained by mass transfer limitations. In the experiments to obtain the response with respect to glucose concentration, each data point for every single enzymatic reaction was collected in not less than $10 \mathrm{~min}$. However, these data were collected for free enzymes in calibration curve experiments within a few seconds, and not for more than $30 \mathrm{~s}$. Therefore, it is quite clear that the system is controlled by the diffusion of the substrate, glucose, through the amyloid matrix. The movements of the substrate (glucose) to the enzyme and the product (hydrogen peroxide) to the electrode surface require more time than the reaction kinetics over the enzyme surface. This very slow diffusion-reaction-diffusion mechanism is directly related to the "effectiveness factor" and "Thiele modulus" of the system and will be investigated in our forthcoming research, similar to our previous studies [17]. Similarly, the response current values of the membrane prepared with the conditions used for "Sample A" were converted to apparent enzymatic activity by the calibration curve. The highest attainable response was observed for the membrane collected at $1 \mathrm{~min}$, and the corresponding enzyme activity was $2547 \pm$ $132 \mathrm{U} / \mathrm{m}^{2}$.

\section{Conclusion}

In this study, a biocatalytic nanofibrous membrane was successfully prepared by electrospinning. First, the damage caused by TFE was minimised by making the protein solution electrospinnable with a 1.5:1.0 (v:v) TFE:PBS ratio. For this ratio, fibres showed more uniform structures with smaller diameters compared to other samples prepared

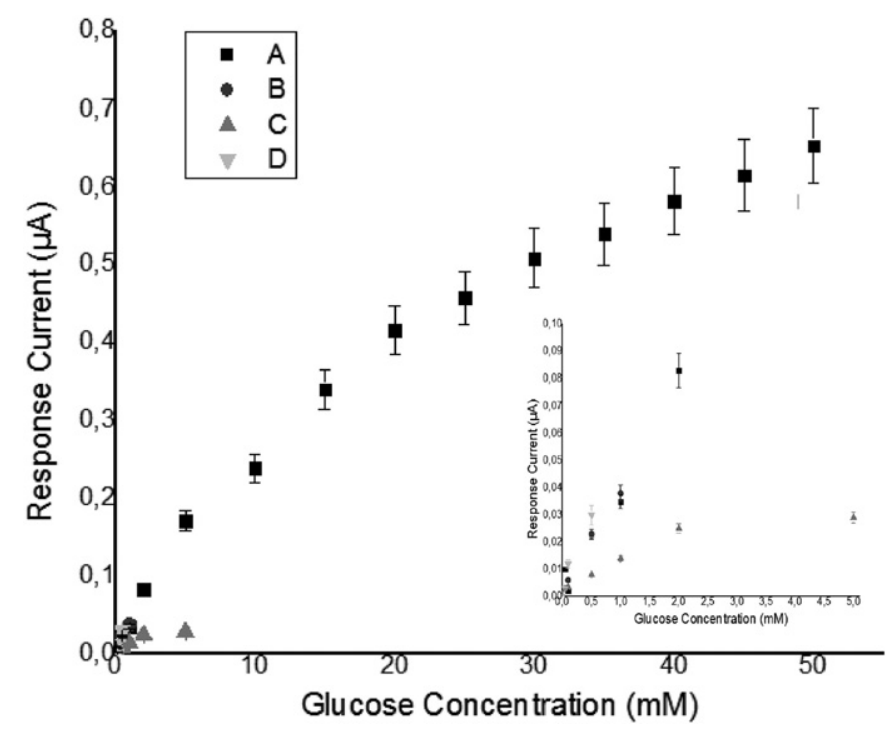

Fig. 6. Changes in response current with glucose concentration at the membranes prepared by different volume ratios of TFE:PBS (A) 1.5:1.0, (B) 3.0:1.0, (C) 4.5:1.0 and (D) 9.0:1.0. Electrospinning conditions; BSA concentration (12\% (w:v)), enzyme concentration $(200 \mathrm{U} / \mathrm{mL})$, voltage $(12 \mathrm{kV})$, tip-to-collector distance $(10 \mathrm{~cm})$, accumulation time (5 $\mathrm{min})$. 


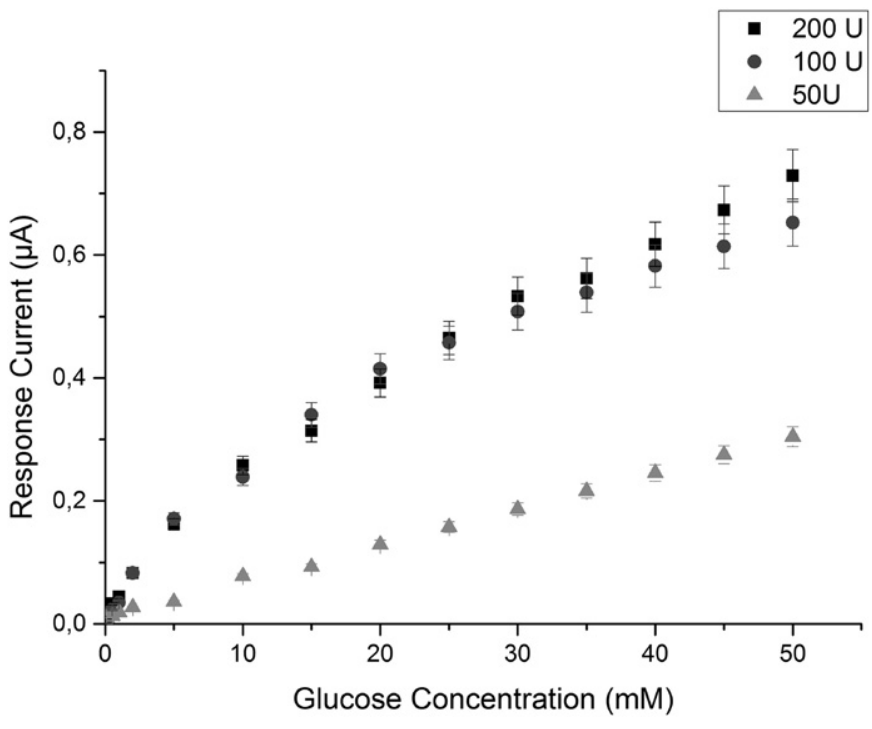

Fig. 7. Changes in response current with initial GOD activity in the electrospinning membrane versus glucose concentration. All electrospinning membranes were containing 12\% BSA (w:v), 1.5:1.0 (v:v) TFE:PBS (pH:7,4), 10 eq. bond $\beta-M E$ (Sample A). To activate membranes biologically, $200 \mathrm{U} / \mathrm{mL}, 100 \mathrm{U} / \mathrm{mL}$ and $50 \mathrm{U} / \mathrm{mL}$ GOD were added to the solution. Electrospinning parameters; voltage, flow rate, tip-to-collector distance and accumulation time were $12 \mathrm{kV}, 0.35 \mathrm{~mL} / \mathrm{h}, 10 \mathrm{~cm}$ and $1 \mathrm{~min}$, respectively.

with higher TFE:PBS ratios. The enzymatic activity for this membrane was also greater than that of the others, which proved that it was the most favourable membrane for biocatalytic applications. The effect of electrospinning parameters on membrane morphology was determined by changing the applied voltage, flow rate, and distance. Below $9 \mathrm{kV}$, a Taylor cone did not form and above $12 \mathrm{kV}$, ruptures were observed. For a flow rate of less than $0.35 \mathrm{~mL} / \mathrm{h}$, no Taylor cone formed and above $0.50 \mathrm{~mL} / \mathrm{h}$, the Taylor cone was unstable. If the distance between the tip and the collector was less than $10 \mathrm{~cm}$, nanofibres did not form and above $20 \mathrm{~cm}$, the jet was not able to reach the collector. Enzyme activity did not increase proportionally with accumulation time owing to mass transfer limitations. Similarly, the increase in enzyme activity was highly limited when the enzyme content in the membrane was doubled. This study provides a simple and efficient technique for entrapping

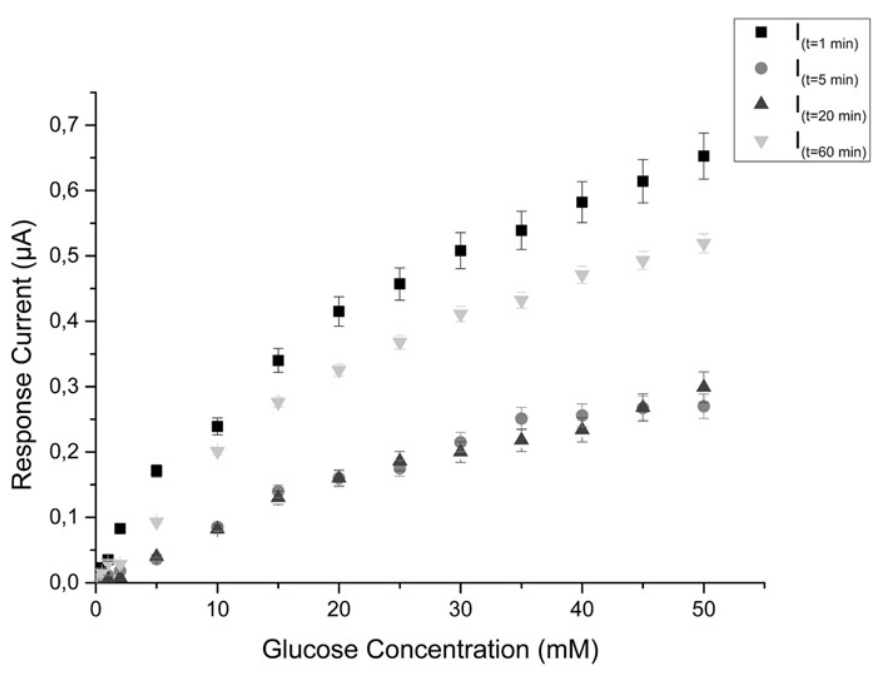

Fig. 8. Changes in response current with accumulation time of electrospinning membrane versus glucose concentration. Sample A was used as an electrospinning solution. Electrospinning parameters; voltage, flow rate tip-to-collector distance were $12 \mathrm{kV}$, $0.35 \mathrm{~mL} / \mathrm{h}, 10 \mathrm{~cm}$, respectively. an enzyme inside protein nanofibres; the method has several applications and can be used to develop biosensors in the future.

\section{Acknowledgements}

The authors express their gratitude to TUBA-GEBIP award as well as the Scientific and Technological Research Council of Turkey (TÜBITAK) for financial support (project no: 215Z047) during the course of this work.

\section{References}

[1] G. Ren, X. Xu, Q. Liu, J. Cheng, X. Yuan, L. Wu, Y. Wan, Electrospun poly(vinyl alcohol)/glucose oxidase biocomposite membranes for biosensor applications, React. Funct. Polym. 66 (12) (2006) 1559-1564.

[2] A. Greiner, J.H. Wendorff, Electrospinning: a fascinating method for the preparation of ultrathin fibers, Angew. Chem. Int. Ed. 46 (30) (2007) 5670-5703.

[3] D. Liang, B.S. Hsiao, B. Chu, Functional electrospun nanofibrous scaffolds for biomedical applications, Adv. Drug Deliv. Rev. 59 (14) (2007) 1392-1412.

[4] W. Ji, Y. Sun, F. Yang, J.J. van den Beucken, M. Fan, Z. Chen, J.A. Jansen, Bioactive electrospun scaffolds delivering growth factors and genes for tissue engineering applications, Pharm. Res. 28 (6) (2011) 1259-1272.

[5] J.S. Park, Electrospinning and its applications, Adv. Nat. Sci. Nanosci. Nanotechnol. 1 (4) (2011) 043002.

[6] D. Rodoplu, M. Mutlu, Effects of electrospinning setup and process parameters on nanofiber morphology intended for the modification of quartz crystal microbalance surfaces, J. Eng. Fibers Fabr. 7 (2) (2012) 118-123.

[7] L. Huang, K. Nagapudi, R.P. Apkarian, E.L. Chaikof, Engineered collagen-PEO nanofibers and fabrics, Journal of biomaterials science, Polym. Ed. 12 (9) (2001) 979-993.

[8] J. Xie, Y.L. Hsieh, Ultra-high surface fibrous membranes from electrospinning of natural proteins: casein and lipase enzyme, J. Mater. Sci. 38 (10) (2003) 2125-2133.

[9] D.B. Khadka, D.T. Haynie, Protein and peptide-based electrospun nanofibers in medical biomaterials, Nanomedicine: Nanotechnology, Biol. Med. 8 (8) (2012) 1242-1262.

[10] Y. Dror, T. Ziv, V. Makarov, H. Wolf, A. Admon, E. Zussman, Nanofibers made of globular proteins, Biomacromolecules 9 (10) (2008) 2749-2754.

[11] T. Kowalczyk, A. Nowicka, D. Elbaum, T.A. Kowalewski, Electrospinning of bovine serum albumin. Optimization and the use for production of biosensors, Biomacromolecules 9 (7) (2008) 2087-2090.

[12] A. Raheja, A. Agarwal, V. Muthuvijayan, T. Chandra, T. Natarajan, Studies on encapsulation of bovine serum albumin, lysozyme and insulin through coaxial electrospinning, J. Biomater. Tissue Eng. 3 (6) (2013) 669-672.

[13] C.P. Barnes, M.J. Smith, G.L. Bowlin, S.A. Sell, T. Tang, J.A. Matthews, D.G. Simpson, J.C. Nimtz, Feasibility of electrospinning the globular proteins hemoglobin and myoglobin, 1 (2) (2006) 16-29.

[14] D. Long, W. Lu, Y. Zhang, Q. Guo, Z. Xiang, A. Zhao, New insight into the mechanism underlying fibroin secretion in silkworm, Bombyx mori, FEBS J. 282 (1) (2015) 89-101.

[15] S. Inoue, K. Tanaka, F. Arisaka, S. Kimura, K. Ohtomo, S. Mizuno, Silk fibroin of Bombyx mori is secreted, assembling a high molecular mass elementary unit consisting of H-chain, L-chain, and P25, with a 6:6:1 molar ratio, J. Biol. Chem. 275 (51) (2000) 40517-40528.

[16] L. Römer, T. Scheibel, The elaborate structure of spider silk, Prion 2 (4) (2008) 154-161.

[17] D.M. Widmaier, C.A. Voigt, Quantification of the physiochemical constraints on the export of spider silk proteins by Salmonella type III secretion, Microb. Cell Factories 9 (1) (2010) 1.

[18] T. Scheibel, Spider silks: recombinant synthesis, assembly, spinning, and engineering of synthetic proteins, Microb. Cell Factories 3 (1) (2004) 14

[19] H. Puchtler, F. Sweat, M. Levine, On the binding of Congo red by amyloid, J. Histochem. Cytochem. 10 (3) (1962) 355-364.

[20] M. Mutlu (Ed.), Biosensors in Food Processing, Safety, and Quality Control, CRC Press, Florida, 2011.

[21] Z.R. Lü, L. Shi, J. Wang, D. Park, J. Bhak, J.M. Yang, Y.D. Park, H.W. Zhou, F. Zou, The effect of trifluoroethanol on tyrosinase activity and conformation: inhibition kinetics and computational simulations, Appl. Biochem. Biotechnol. 160 (7) (2010) 1896-1908.

[22] V. Jacobs, R.D. Anandjiwala, M. Maaza, The influence of electrospinning parameters on the structural morphology and diameter of electrospun nanofibers, Journal of Applied Polymer Science 115 (5) (2010) 3130-3136.

[23] V. Jacobs, R.D. Anandjiwala, M. Maaza, The influence of electrospinning parameters on the structural morphology and diameter of electrospun nanofibers, J. Appl. Polym. Sci. 115 (5) (2010) 3130-3136.

[24] J. Shi, L. Wang, F. Zhang, H. Li, L. Lei, L. Liu, Y. Chen, Incorporating protein gradient into electrospun nanofibers as scaffolds for tissue engineering, ACS Appl. Mater. Interfaces 2 (4) (2010) 1025-1030.

[25] V. Pillay, C. Dott, Y.E. Choonara, C. Tyagi, L. Tomar, P. Kumar, L.C. du Toit, V.M. Ndesendo, A review of the effect of processing variables on the fabrication of electrospun nanofibers for drug delivery applications, J. Nanomater. 2013 (2013) 789289.

[26] F. Ruggeri, G. Longo, S. Faggiano, E. Lipiec, A. Pastore, G. Dietler, Infrared nanospectroscopy characterization of oligomeric and fibrillar aggregates during amyloid formation, Nat. Commun. 6 (2015) 1-9. 
[27] A. Kausaite-Minkstimiene, V. Mazeiko, A. Ramanaviciene, A. Ramanavicius, Evaluation of amperometric glucose biosensors based on glucose oxidase encapsulated within enzymatically synthesized polyaniline and polypyrrole, Sensors Actuators B Chem. 158 (1) (2011) 278-285.

[28] M. Desai, M. Mutlu, P. Vadgama, A study of macromolecular diffusion through native porcine mucus, Experientia 48 (1) (1992) 22-26.

[29] Z. Koochaki, S.P. Higson, M. Mutlu, P.M. Vadgama, The diffusion limited oxidasebased glucose enzyme electrode: relation between covering membrane permeability and substrate response, J. Membr. Sci. 76 (2) (1993) 261-268.

[30] M. Mutlu, S. Mutlu, The effect of crosslink density on permeability in biosensors: an unsteady-state approach, Biotechnol. Tech. 9 (4) (1995) 277-282.
[31] S. Mutlu, M. Mutlu, E. Piskin, A kinetic approach to oxidase based enzyme electrodes: the effect of enzyme layer formation on the response time, Biochem. Eng. J. 1 (1) (1998) 39-43.

[32] M. Mutlu, S. Mutlu, I.H. Boyaci, B. Alp, E. Piskin, High-Linearity Glucose Enzyme Electrodes for Food Industries: Preparation by a Plasma Polymerization Technique in "Polymers in Sensors: Theory and Practice", in: N. Akmal, A.M. Usman (Eds.),American Chemical Society (ACS) Symposium Series, 690 1998, pp. 57-65.

[33] S. Mutlu, M. Mutlu, P. Vadgama, E. Piskin, Sandwich-type amperometric enzyme electrodes for determination of glucose in "Diagnostic Polymeric Materials", in: A.M. Usmani, N. Akmal (Eds.),American Chemical Society (ACS) Symposium Series, 556 1994, pp. 71-83. 